\title{
$O$ veredito dos deuses? Aspectos sobre a análise de provas judiciais e a delicada relação entre direito e religião nos processos paleobabilônicos
}

Em memória de Emanuel Bouzon e seus 5 anos de falecimento Andréa Cláudia Rodrigues Barbosa M.A.

\section{Resumo}

Os processos eram documentos privados, de caráter legal, que eram guardados pela parte vencedora com o objetivo de ter seu direito assegurado. As fontes deste trabalho provêm do chamado período paleobabilônico, que se estende do século 19 até 16 a.C. Sob o conceito "paleobabilônico" deve se entender aspectos culturais e linguísticos. Por um lado, trata-se de um dialeto do acádico e, por outro lado, se refere às mudanças políticas que acarretaram a unificação das cidades mesopotâmicas sob a hegemonia da Babilônia.

Este trabalho tem como objetivo apresentar os aspectos religiosos do procedimento de provas nos julgamentos paleobabilônicos. Esta seção situa-se na metade do processo, entre a abertura do julgamento e o término da disputa. Em relação ao procedimento de provas podem-se reconhecer várias situações: o juramento e sua terminologia religiosa, os lugares do juramento e seus rituais com símbolos divinos. Todos estes fatores eram decisivos para a conclusão da disputa. A sentença do tribunal era transmitida às partes após a investigação religiosa.

Palavras-chave: Assiriologia, Direito, Mesopotâmia, Religião. 


\section{Zusammenfassung}

Die Prozessurkunden waren private Rechtsdokumente, die bei der siegreichen Partei aufbewahrt wurden, um sich rechtlich abzusichern. Die Quelle dieser Arbeit stammt aus der so genannten altbabylonischen Zeit, die sich von dem 19. bis 16. Jh. v. Chr. erstreckt. Mit dem Begriff, altbabylonisch“ sind sprachliche und kulturelle Aspekte gemeint. Auf der einen Seite handelt es sich um den Dialekt des Akkadischen und auf der anderen Seite um die politische Veränderung, die Mesopotamien zu der Vereinigung seiner Städte unter Babylons Hegemonie hingeführt hat.

Diese Arbeit hat das Ziel, die religiösen Aspekte des Beweisverfahrens in den altbabylonischen Verhandlungen darzustellen. Dieser Abschnitt steht in der Mitte der Prozessurkunden, zwischen der Eröffnung des Verfahrens und der Beendigung des Rechtsstreits. Bei dem Beweisverfahren sind mehrere Teilbereiche zu erkennen: Der Eid und seine religiöse Terminologie, die Eidstätte und die Rituale mit den Göttersymbolen. All diese Faktoren waren für die Urteilsfindung des Rechtsaustrags entscheidend. Das Urteil des Gerichts wurde erst nach einer religiösen Untersuchung an die Parteien übermittelt.

Schlagwörter: Assyriologie, Recht, Mesopotamien, Religion.

\section{Introdução}

Este trabalho é parte da investigação realizada para a tese de doutorado Untersuchung zu den altbabylonischen Prozeßurkunden unter besonderer Berücksichtigung des Grundeigentums und seiner widerrechtlichen Besitzergreifung, que está sendo desenvolvida no Institut für Altorientalische Philologie und Vorderasiatische Altertumskunde na Westfälische WilhelmsUniversität Münster, Alemanha, sob a supervisão do Prof. Dr. Hans Neumann. Nossa tese analisa os processos jurídicos paleobabilônicos quanto a sua terminologia e conteúdo, tendo como cerne o problema da disputa pela propriedade imobiliária e seu significado jurídico e social.

A estrutura de um processo paleobabilônico pode ser bastante complexa dependendo do documento que se tem em vista, pois existem formas mais extensas e ao lado destas, formas mais compactas deste tipo de material. Uma completa apresentação das estruturas envolvidas escapa aos objetivos desta 
comunicação e mesmo ao tema deste simpósio, por isso nos limitamos apenas a apresentar e comentar a seção do processo investigativo de provas, o seu caráter religioso e determinante para a emissão da sentença.

Apesar de ser um assunto ligado especialmente à assiriologia, à história do direito e à história antiga, o tema possui especial relevância para a discussão teológica, pois aborda a delicada relação entre a experiência religiosa mesopotâmica e sua relação com a esfera jurídica. Os rituais religiosos de caráter simbólico e a observância do rito e os juramentos, realizados no templo ou mesmo fora deste, representavam o ponto central do processo. A importância da investigação religiosa pode ser verificada nos chamado documentos pré-processuais, que relatam situações onde as partes temiam o processo investigativo e o julgamento não era iniciado, resultando num acordo entre elas.

Finalizando esta introdução, gostaria de agradecer as contribuições do cientista político e irmão, F. Rodrigues Barbosa M.A., do jurista Henrique Barahona M.A., ambos membros do laboratório Cidade e Poder da UFF e suas valiosas contribuições concernentes a atual discussão sobre a inserção do discurso religioso e concepções teológicas na história do direito e da política. Um agradecimento especial a amiga e arqueóloga Erika Gitt M.A., WWU-Münster, pelo envio periódico de artigos, desde que retornamos a nossa terra natal, ao fomento Capes-DAAD que tornou possível este trabalho e a comissão científica do departamento de teologia da PUC que o selecionou para a apresentação.

\section{Os processos paleobabilônicos: Uma breve apresentação estrutural}

O termo paleobabilônico abrange aspectos linguísticos e culturais. Por um lado, aponta um dos vários dialetos da língua acádica, no qual a maioria dos documentos datados da metade do segundo milênio a.C. foi redigida. Por outro lado, indica também o cenário político, econômico, religioso e cultural que predominou na Mesopotâmia entre os séculos 19-16 a.C. Durante este período a dinastia de Hammurabi se tornou a mais proeminente, colocando as cidades-estados mesopotâmicas sob a hegemonia da Babilônia ${ }^{1}$.

\footnotetext{
${ }^{1}$ Cf. Klengel, H., König Hammurapi und der Alltag Babylons. Artemis \& Winkler, Berlin, 1991, pp. 11-14: Este processo político e também militar é chamado pelos historiadores e assiriólogos como "unificação mesopotâmica". Particularmente considero este termo inapropriado, pois deturpa o desenrolamento dos acontecimentos históricos.
} 
O período paleobabilônico deixou para a posteridade uma quantidade considerável de documentação jurídica, como contratos de compra e venda, aluguéis, empréstimos, herança, coleções legais, editos reais entre outros. E como partes desta rica documentação encontram-se os chamados processos jurídicos.

A caracterização formal como "processo" é algumas vezes problemática, pois é utilizada em larga escala pelos assiriólogos, sem fazer distinção entre os documentos quanto ao seu caráter tipológico. Então sob a denominação "processo" estão também documentos que possuem como conteúdo o encerramento de uma disputa, documentos que apresentam o encerramento ainda em fase pré-processual, memorandos e toda sorte de procedimentos judiciais não necessariamente litigiosos ${ }^{2}$.

Os processos jurídicos eram documentos de prova de caráter privado, ao contrário de outros documentos judiciais, que eram guardados no arquivo do tribunal. Os processos foram redigidos com a intenção de proteger o direito adquirido de uma das partes contra futuras reivindicações. Dentre estes, existem processos que relatam desde um julgamento inteiro, com todas as suas etapas jurídicas até aqueles que possuem um formato mais compacto, apresentando somente algumas seções da disputa jurídica ou da atividade do julgamento ${ }^{3}$. Estruturalmente sem ulteriores detalhes quanto às divisões internas de cada seção, um processo jurídico paleobabilônico possui a seguinte forma ${ }^{4}$ :

Fórmula de Introdução

Abertura do processo

Análise de provas

\footnotetext{
${ }^{2}$ Cf. Dombradi, E., Die Darstellung des Rechtsaustrags in den altbabylonischen Prozessurkunden. Band 1, Franz Steiner Verlag, Stuttgart, 1996, p. 09.

${ }^{3}$ Cf. op. cit., pp. 11-12.

${ }^{4}$ Cf. op. cit., pp. 168.169: Segundo Eva Dombradi e sua análise tipológica dos processos civis, algumas seções podem ser deixadas de lado durante a redação do documento. Ou seja, existem processos em que uma ou mais etapas faltam. Todavia, existem etapas que nunca estão ausentes, como a introdução, o impedimento quanto a futuros julgamentos, as testemunhas e a data. Cf. Lautner, J., Die richterliche Entscheidung und die Streitbeendigung in altbabylonischen Prozessrechte. Verlag von Theodor Weicher, Leipzig, 1922, pp. 06-67: Anteriormente a Eva Dombradi, Lautner escreveu um livro onde discutiu em particular o poder de homologação das sentenças emitidas pelos juízes paleobabilônicos. Para isso, analisou também a tipologia e terminologia processual. A análise de Lautner ainda possui grande valor para a investigação do direito paleobabilônico e para a análise terminológica processual. Porém, sua classificação dos processos como arbitragens e sua conclusão de que a sentença por esta razão não possuía força coercitiva, é a nosso ver, um equívoco.
} 
Decisão da disputa

Prestação das partes

Fórmula de impedimento - conclusão

Lista de testemunhas

Selo

Data

\section{A análise meritória das provas}

Como informado anteriormente, escapa aos propósitos deste trabalho comentar em detalhes toda a estrutura de um processo paleobabilônico e seu significado jurídico. Ao contrário, este se concentra unicamente na seção central do processo, que parece ter um papel decisivo na emissão da sentença ou mesmo na decisão anterior das partes, de procurar ou não a via judiciária.

A seção de análise de provas vem descrita logo após a abertura do processo. Em alguns casos aparece sucinta, sem maiores detalhes sobre o processo de investigação e suas etapas. A única menção é a frase di.ku $\mathbf{5}_{5} \cdot \mathbf{m e s ̌}$

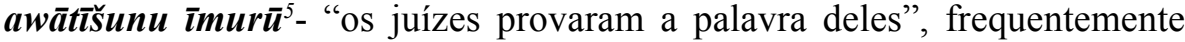
discutida nos últimos anos. O sentido desta frase pode ser em breves palavras dividido entre duas posições principais. A primeira interpreta a frase como a verificação do valor de mérito das provas ${ }^{6}$. $\mathrm{O}$ objeto em si da verificação judicial não seria o depoimento das partes, mas ao contrário, seria as relações de direito das partes com o objeto, apresentadas durante o depoimento, para provar seu direito a ele ou mesmo sua reivindicação. A segunda posição defende que esta frase sugere unicamente a apresentação do depoimento das partes e suas contradições?

\footnotetext{
${ }^{5}$ Cf. Dombradi, E., op. cit., Band 2, nota 341, p. 83: Esta frase pode ocorrer também no início, logo na fórmula de abertura do processo e ali deve ser entendido, como a verificação dos pressupostos para o início do processo, como segundo a autora parece ser o caso em TIM IV 5-6.

${ }^{6}$ Ries, G., altbabylonische Beweisurteile“. Zeitschrift der Savigny-Stiftung für Rechtsgeschichte. 106 (1989), pp. 56-80. O artigo comenta de forma abrangente o sentido desta frase.

${ }^{7}$ Cf. Lautner, J., op. cit., pp. 32-33; Schorr. M., Urkunden des altbabylonischen Zivil- und Prozessrechts. J. C. Hinrich'sche Buchhandlung, Leipzig, 1913, p. 347. Cf. também Dombradi. E., op. cit., Band 1, pp. 328-329. Apesar do trabalho de Eva Dombradi ser mais recente e completo quanto à análise tipológica dos processos, nós assumimos a primeira posição. $\mathrm{O}$ fato de a frase estar no plural não é suficiente para esvaziá-la de seu significado jurídico, como esta propôs em seu trabalho.
} 
Algumas etapas da investigação são descritas nesta seção, como o juramento, os rituais simbólicos, as testemunhas, a chamada burru/kunnu citação. Além destas, observa-se também a ocorrência da prova documental. O ordálio apesar de ser atestado pelo código de Hammurabi se encontra ausente na documentação processual ${ }^{8}$. Estas etapas não aparecem todas de uma vez em cada processo. Elas podem aparecer de forma isolada ou em diferentes combinações como será apresentado em seguida. Todas estas etapas investigativas são permeadas de rituais e terminologia jurídicas e religiosas e decisivas para a emissão da sentença.

Os processos civis paleobabilônicos conhecem dois tipos de juramento: $\mathrm{O}$ assertório e o promissório. Nesta seção encontra-se o primeiro, que realizado durante o depoimento, assegura a veracidade daquilo que é dito sobre um evento no presente e no passado. O juramento era realizado diante do deus local, sendo com isso, o instrumento mais importante para a verificação da verdade. Havia o chamado juramento negativo, sob o uso do verbo ubbubu que era aplicado ao processado, que através deste deveria se "purificar" de uma suspeita ou acusação que o requerente fazia contra ele. Por isso, é chamado de juramento de purificação ${ }^{9}$. Em geral, o juramento era aplicado ao processado. Juramentos aplicados aos requerentes eram mais raros e ocorriam em situações especiais ${ }^{10}$.

O juramento era algo determinado pelos juízes, que também estabeleciam como seriam realizados ${ }^{11}$. A realização do juramento constituía prova irrevogável do direito do processado. Era realizado em geral no portão do templo, para onde as partes, as testemunhas, os juízes e também os sacerdotes se encaminhavam e do evento participavam. A língua acádica paleobabilônica conhece uma terminologia específica para indicar os locais deste, como bāb nī̌s ili "portão do juramento ao deus", ou ainda ašar māmītim "cidade do juramento" e ana pāni papāhim "diante do santuário" juramento não aparece nos processos, porém consta a descrição de um ritual religioso diante do símbolo da divindade, que descreve as circunstâncias do

\footnotetext{
${ }^{8}$ Cf. Dombradi, E., op. cit. Band 1, p. 338. Existe uma única ocorrência para o uso do ordálio, que é o caso de CT $2942 / 43$.

${ }^{9}$ Cf. Schorr, M., op. cit. pp. 348-349.

${ }^{10}$ Cf. Dombradi, E., op. cit. Band 1, p. 330. Cf. Schorr. M., Ibid.

${ }^{11}$ Uma excessão parece ser o caso de VS 22, 28, onde o requerente determina todas as etapas do juramento e todas as etapas da investigação religiosa.

${ }^{12}$ Cf. Dombradi, E., op. cit. p. 332. Cf. também Schorr, M., Ibid.
} 
juramento ${ }^{13}$. Estes rituais religiosos também eram realizados fora do templo, como aponta VS 22, 28 e Gautier 13. A linguagem utilizada para descrever estes eventos é muitas vezes interpretada pela assiriologia como sendo "fantasiosa", mas um olhar mais atento e respeitoso irá indicar que ela nada tem de "fantasiosa", mas expressa a crença profunda dos mesopotâmicos na participação dos deuses durante o julgamento. Os símbolos divinos se moviam até o lugar da investigação. Eles não aparecem descritos como objetos sagrados que são levados até lá, mas como entidades autônomas, capazes de se movimentar. Os termos utilizados são verbos de movimento como alākum "andar, caminhar", erēbu "entrar, adentar", izuzzum "entrar", wašābum "sentar"14.

Um exemplo de um ritual realizado fora do templo provém cidade de Dilbat. Logo após a abertura do processo, o ritual aparece sumariamente descrito. Logo depois os juízes emitem a sentença. Aqui foi feito um corte no texto, para apresentar unicamente a investigação religiosa:

\section{Gautier 13}

08 iş-ra-at ša duraš $a-n a$ é-im
${ }_{09} \quad \boldsymbol{i r}-\boldsymbol{d u}$-ú-ma
${ }_{10}$ é-am ú-sa-an-ni-qú-ma
${ }_{11} \quad 1$ sar é i-te-ir-ma

Traduzindo:

08-09 Eles acompanharam o símbolo de Uraš até a propriedade e

10 mediram a propriedade $\mathrm{e}$

11 a propriedade fôra alargada em 1 Sar

Outro exemplo encontra-se em um processo oriundo da cidade da Babilônia em VS 22, 28, que aponta após o ritual realizado no templo, a exigência de outro ritual, num outro distrito no terreno em litígio:

\footnotetext{
${ }^{13}$ Idem.

${ }^{14}$ Cf. Dombradi, E., op. cit. Band 2, nota 2206, p. 275. A autora aponta para o fato de que os verbos izuzzum "entrar", e wašābum "sentar" são também termos técnicos da atuação dos juízes durante o julgamento, que "entram e sentam para julgar". A menção isolada do verbo no processo já indica a atividade judicial a ele relacionada.
} 
VS 22, 28

md amar.utu-ka-ši-id $i$-na é damar.utu

ki-a-am iq-bi um-ma šu-ma

be-lu é ù ši-bu-šu-nu

$a-n a$ bur.zi.bi.šur ${ }^{\mathrm{KI}} l i-s ̧ u ́-u ́$

gištukul $\check{s} a^{d} z a-b a_{4}-b a_{4} l i-i \check{s}-s ̌ a-k i-i n-m a$

i-ta i-ta é-šú-nu li-bi-ir-ru

md amar.utu-ka-ši-id an-ni-tam iq-bi-ma

${ }^{\mathrm{m}} i-b i$ - den.zu dub.sar zag.ga ${ }^{\mathrm{m}} i b-n i-{ }^{\mathrm{d}} \mathrm{utu}<\mathrm{gal}>$.di.ku ${ }_{5}$. [meš]

$a-n a$ bur.zi.bi.šur ${ }^{\mathrm{KI}} \dot{u}$-şú-ú-ma

gišstukul ${ }^{d} z a-b a_{4}-b a_{4}{ }^{d} k a-m i-t a-m i-\check{s} u$

$i \check{s}-\check{s} a-k i-i n-m a$

$5 \frac{1}{2}$ sar é $i$-ta be-el-šsu-nu [xxxxxxxxxxxx] $]^{15}$

ù $i$-ta ${ }^{\mathrm{d}}$ na-bi-um-ma-lik ŠU.(I)

sağ.bi é gi-mil d $g u_{10}-l a m u-<s ̌ i>-<i b>$

egir-sú é den.zu-pí-la-aḥ ù sig- $A$-lra $\mathrm{ra}^{]}$[ah]-[tum]

$a-n a$ a-wi-il- ${ }^{\mathrm{d}} m i-s ̌ a-r u m$ ugula. mar.tu

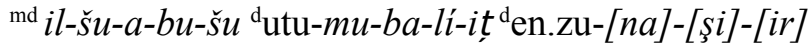

Mí be-el-ta-ni ù ìr-[ ${ }^{\mathrm{d}}$ taš-me-tum]

be-lu é

md $z a-b a_{4}-b a_{4}$-na-şi-ir ra-bi-a-[nu]

md en.zu-i-din-nam dumu šu-[ešs-tár]

md $l u$-hu-šsum-mu-ša-lim dumu ili-ḥa-[xxxxxxx]

${ }^{\mathrm{m}} i b-n i$ - ${ }^{\mathrm{d}}$ amar.utu dumu be-la [xxxxxxxxx]

md amar.utu-li-wi-ir dumu i-li -[ $\mathrm{xxxxxx]}$

md $z a-b a_{4}-b a_{4}-n i-\check{s} u$

${ }^{\mathrm{m}} i b-n i-{ }^{\mathrm{d}}$ amar.utu dumu $i$-din- ${ }^{\mathrm{d}}[\mathrm{en}] .[\mathrm{zu}]$

md amar.utu-ni-šu dumu ri-im-[xxxxxxx]

${ }^{\mathrm{m}} u$ útúl-e $\check{s}_{4}$-tár dumu sağ-[xxxxxxx]

${ }^{\mathrm{m}} i l-s ̌ s u-n a-s ̧ i-i r$ dumu i-lí-[xxxxxx]

m $n a-b i-u m-n a-s ̧ i-i r$ dumu $s i-[\mathrm{xxxxx}]$

ù ši-bu-ut bur.zi.bi.šur ${ }^{\mathrm{KI}} \dot{u}$-bi-ir-[ru]

${ }^{15} \mathrm{O}$ texto que aparece como $[\mathrm{xxxxx}$ ] indica que a tábua se encontra quebrada neste ponto da frase, impossibilitando que todo o conteúdo dela seja decifrado e traduzido. 


\section{Traduzindo:}

Marduk-Kašid no templo de Marduk disse o seguinte:

Os senhores da propriedade e suas testemunhas devem ir até BUR.ZI.BI.ŠUR ${ }^{\mathrm{KI}}$.

A arma do deus Zababa deve ser colocada.

Eles devem verificar sua propriedade lado a lado.

Assim disse Marduk-Kašid

Ibbi-Sîn, diretor cadastral und Ibni-Šamaš, o supremo juiz foram até BUR.ZI.BI.ŠUR ${ }^{\mathrm{KI}}$.

A arma do deus Zababa „o comprometimento de seu juramento“

foi colocada.

$5 \frac{1}{2}$ SAR da propriedade de Bēlšunu

e de Nabium-Malik, o barbeiro.

A frente de sua propriedade é a moradia de Gimil-Gula, seu reverso é a propriedade de Sîn-Pilaḥ und Ipqu-Araḥtum.

Para Awîl-Mišarum, guarda dos amurrûs,

Ilšu-Abušu, Šamaš-Mubalit, Sîn-Nasir,

Bēltani und Warad-[Tašmētum],

os senhores da propriedade, (e também para $)^{16}$

Zababa-Nasir, o prefeito, Sin-Idinnam, filho de Šu[Ištar], LuhušumMušalim, filho de Ili-Ḥa, Ibni-Marduk, filho de Bela, Marduk-Liwwir, filho de Ili, Zababa-Nīšu, Ibni-Marduk, filho de Idīn-[Sin], Marduk-Nī̌su, filho de Rīm, Utul-Ištar, filho de Rēš, Ilšu-Nasir, filho de Ili, Nabium-Nasir, filho de Si, e aos antigos des BUR.ZI.BI.ŠURR ${ }^{\mathrm{KI}}$ provaram .

Algumas vezes a descrição de juramentos e rituais não é narrada no processo. Em seu lugar aparece uma citação sobre o sucesso quanto à obtenção de provas. É a chamada burru/kunnu citação. O verbo burru no tronco D "provar, investigar", de bâru que no tronco G significa "aparecer, surgir" é um termo técnico para a obtenção de provas através dos mecanismos religiosos e cúlticos. Logo, ao invés de uma narrativa descrevendo os rituais, lê-se unicamente uma frase afirmando que uma das partes conseguiu provar o seu direito ${ }^{17}$.

\footnotetext{
${ }^{16}$ Fiz uma pequena inserção na tradução no texto neste ponto, apenas para ilustrar que os processados neste caso, aqui chamados pelo requente como "senhores da propriedade", tiveram de provar também a todas estas testemunhas o seu direito a propriedade em questão.

${ }^{17}$ Cf. Dombradi, E., op. cit. Band 1, pp. 89-95.
} 
Como uma última exposição ao tema, é interessante apontar algumas questões sobre a prova documental. Raramente foi utilizada antes da dinastia de Hammurabi, pois não possuía valor em si mesma, já que seu conteúdo deveria ser colocado sob juramento. A partir da primeira dinastia babilônica foi ganhando importância progressiva, porém, sua validade podia ser questionada pelo requerente, como mecanismo de prova. Sendo assim o documento era colocado sob juramento, que através deste, deveria ter sua veracidade comprovada ${ }^{18}$.

Concluindo esta pequena exposição alguns tópicos parecem pertinentes. O primeiro deles está no caráter central da investigação de provas nos julgamentos paleobabilônicos. Pois logo em seguida, era emitida a sentença pelos juízes com base nesta investigação, a favor ou contra o requerente. Esta investigação possuía caráter religioso. Não há como escapar disso. Trata-se da inserção da esfera religiosa mesopotâmica, com seus rituais e sua teologia, na esfera jurídica e ocupando espaço central nela. A investigação jurídica paleobabilônica é investigação religiosa.

Com isto se abre a questão, escrita de forma provocativa no título desta comunicação, sobre o autor do veredito e seu poder coercitivo. Ao lado da esfera jurídica se encontra no mesmo patamar que ela, a religiosa. A sentença proferida pelos juízes e seu poder de vínculo é resultado da ligação entre estas duas esferas.

\section{Referências Bibliográficas}

\section{Edições de museu:}

Cuneiform Texts from Babylonian Tablets in the British Museum. Nr. 2, London, 1896.

Gautier, J., Archives d'une famille de Dilbat au temps de la premiere dynastie de Babylone. Le Caire, 1908.

Vorderasiatische Schriftdenkmäler der königlichen Museen zu Berlin. Heft XXII, Berlin, 1983.

\section{Livros:}

DOMBRADI, E., Die Darstellung des Rechtsaustrags in den Altbabylonischen Prozessurkunden. 2 Bänder. Franz Steiner Verlag, Stuttgart, 1996. KLENGEL, H, König Hammurapi und der Alltag Babylons. Artemis \& Winkler, Berlim, 1991.

\footnotetext{
${ }^{18}$ Cf. Dombradi, E., op. cit. Band 1, p. 338. Contra Schorr in op. cit., pp. 348, onde afirma que a prova documental era a mais importante de todas.
} 
LAUTNER, J., Die richterliche Entscheidung und die Streitbeendigung im altbabylonischen Prozessrechte. Verlag von Theodor Weicher. Leipzig, 1922. SCHORR, M., Urkunden des Altbabylonischen Zivil - und Prozessrechtes. J. C. Hinrich'sche Buchhandlung, Leipizig, 1913.

WALTHER, A., Das Altbabylonische Gerichtswesen. J. C. Hinrich'sche Buchhandlung, Leipizig, 1917.

Artigos:

CHARPIN, D., "Un quartier de Babylone et ses habitants sous les successeurs d'Hammurabi". Bibliotheca Orientalis XLII No 3-4(1985).

KLENGEL, H., Bemerkungen zu den altbabylonischen Rechtsurkunden und Wirtschaftstexten aus Babylon (VS 22: 1-82)“. Altorientalischen Forschungen 10(1983).

RIES, G., Altbabylonische Beweisurteile“. Zeitschrift der Savigny-Stiftung für Rechtsgeschichte. 106 (1989).

Dicionários, Gramáticas e Índices de símbolos cuneiformes:

BORGER, R., Mesopotamisches Zeichenlexikon. Alter Orient und Altes Testament 305, Ugarit Verlag, Münster, 2004.

GELB, I., LANDSBERGER, B., OPPENHEIM, A., REINER, E., The Assyrian Dictionary of the Oriental Institute of the University of Chicago. 25 Bänder, Fourth Printing, Published by the Oriental Institute Chicago and J. J. Augustin Verlagsbuchhandlung, Glückstadt, 1998.

LABAT, R., Manuel $D^{\prime}$ Épigraphie Akkadienne. $6^{\circ}$ Édition, Librairie Orientaliste Paul Geuthner S.A, Paris, 1999.

VON SODEN, W., Grundriss der Akkadischen Grammatik. Pontificium Institutum Biblicum, Roma, 1952. , Akkadisches Wörterbuch. 3 Bänder. Otto Harrassowitz,

Wiesbaden, 1965.

Andréa Cláudia Rodrigues Barbosa

Bacharel em Teologia pela PUC-Rio no ano de 2002.

Mestrado em Teologia Bíblica, em direito veterotestamentário em 2005.

Desde 2006 é doutoranda em Assiriologia na WWU-Münster, Alemanha. Atualmente é colaboradora do Laboratório do Antigo Oriente Próximo da USP.

Artigo Recebido em 06/09/2011. Artigo Aprovado em 16/11/2011. 